\title{
Una lectura del teatro de Laila Ripoll: cuerpos de mujeres rotos'
}

\author{
A Theater Reading of Laila Ripoll:Women's Broken Bodies
}

\author{
ADELINA LAURENCE \\ Universidad de Poitiers \\ Francia \\ adelina37@hotmail.fr
}

(Recibido: I9-09-20I6; aceptado: $05^{-0} 5^{-2 O I 7)}$

Resumen. El cuerpo, indisociable del espíritu, se une a él y nos hace únicos. Pero las guerras, las violencias machistas han lastimado este cuerpo que tanto valoramos. ¿Qué lugar queda, en un mundo obsesionado por el culto a los valores corporales, para los cuerpos mancillados, mutilados, rotos? Cumpliendo con su función catártica sobre la población, el teatro trata de contestar a esta pregunta. Mediante una visión extrema de la corporeidad, la dramaturga Laila Ripoll nos enfrenta, en sus obras Once de marzo, Pronovias, El árbol de la esperanza, El triángulo azul y La ciudad sitiada, a cuerpos de mujeres mutiladas, violadas, de las que han abusado los hombres, la guerra y la sociedad. Nuestro trabajo se propone analizar esta problemática y devolver la palabra a esas mujeres heroicas, ignoradas por nuestra sociedad, pero que luchan sin descanso para aceptar su cuerpo roto, convivir con él y amarlo.

Palabras clave: teatro contemporáneo; Laila Ripoll; imaginario femenino; representaciones del cuerpo.
Abstract. The body, inseparable from the spirit, joins it and makes us unique. Nonetheless, wars and sexist violence have hurt this body we cherish. What place is left in a world obsessed with the cult of corporal values, for defiled, mutilated and broken bodies? Fulfilling its cathartic function over the population, the theater tries to answer this question. Through an extreme view of corporeality, playwright Laila Ripoll confronts us, in her works Once de marzo, Pronovias, El árbol de la esperanza, El triángulo azul, and La ciudad sitiada, with the bodies of mutilated women, raped, which men, war and society have abused. Our job is to analyze this problem and return the word to those heroic women, ignored by our society, but fighting tirelessly to accept their broken body, living with it and loving it.

Keywords: Contemporary Theater; Laila Ripoll; Female Imagination; Representations of the Body.

\footnotetext{
I Para citar este artículo: Laurence, Adelina (20I7). Una lectura del teatro de Laila Ripoll: cuerpos de mujeres rotos. Álabe 16. [www.revistaalabe.com]

DOI: IO.I5645/Alabe2OI7.I6.2
} 
Donnez-moi un corps, c'est la formule du renversement philosophique. Le corps n'est plus l'obstacle qui sépare la pensée d'elle-même, ce qu'elle doit surmonter pour arriver à penser. C'est au contraire ce dans quoi elle plonge ou doit plonger, pour atteindre à l'impensé, c'est à dire à la vie. Non pas que le corps pense, mais obstiné, têtu, il force à penser, et force à penser ce qui se dérobe à la pensée, la vie. On ne fera plus jamais comparaître la vie devant les catégories de la pensée, on jettera la pensée dans les catégories de la vie. Les catégories de la vie, ce sont précisément les attitudes du corps, ses postures (Deleuze, 1985: 246).

\section{Cuerpo, sociedad y teatro}

El cuerpo se considera un elemento esencial en nuestra vida, indisociable del espíritu. La unión del cuerpo y del espíritu hace que seamos quienes somos, individuos diferentes y únicos. El cuerpo se suele considerar como el reflejo del alma. A través de él, la sociedad nos ve y nos percibe, hasta convertirse en una obsesión en nuestro mundo actual. El culto al cuerpo, característica de nuestra sociedad, dicta que tenemos que ser más guapos, más jóvenes y siempre más competentes en todos los ámbitos. Siguiendo esta línea, conviene preguntarse: ¿qué lugar queda para los cuerpos mancillados, mutilados, rotos? ¿Se puede considerar que son el reflejo de un alma rota, mancillada y mutilada también? La respuesta no es sencilla. La historia nos lo enseña tanto en el pasado como hoy en día. Cada individuo es un mundo aparte, cada uno percibe su cuerpo y su relación con los demás de una forma distinta. Cada historia es diferente y por lo tanto única. No nos incumbe juzgarlo.

Los años 6o-7o ven la liberación del cuerpo y la revolución sexual. La mujer adquiere el derecho a disponer de su cuerpo como le plazca y puede vivir su sexualidad abiertamente. Es la teoría. Por desgracia, en la práctica esta afirmación no es tan sencilla, el cambio no es tan radical. Pese a los numerosos avances en cuanto a los derechos de la mujer, seguimos viviendo bajo el yugo de la dominación masculina. Los esquemas tradicionales siguen estando vigentes: el modelo de la familia patriarcal, el papel de la mujer en ella, la visualización del hombre en la esfera pública mientras la mujer se queda en el ámbito familiar, son solo algunos ejemplos de esta relación de dominación/sumisión. El poder masculino, en algunos casos, no es solo simbólico, ni la reproducción de un esquema adquirido en la infancia, sino que supone una violencia real, brutal, y refleja al ser humano en todo lo que tiene de primitivo y abyecto. El número de mujeres víctimas de violencia machista a manos de su pareja o expareja basta para demostrarlo. Siguiendo las normas sociales, los hombres tienen que demostrar su virilidad en todos los ámbitos, las dictaduras o las violaciones son ejemplos de ella (Bourdieu, I998). 
Las relaciones de poder no solo se definen entre hombres y mujeres, sino también entre distintas poblaciones e incluso dentro de una misma sociedad. Las guerras, las relaciones de fuerza, son una constante en el ser humano y definen su trayectoria desde el comienzo de los tiempos. Así, es conveniente preguntarnos: ¿cómo se definen estas guerras por la toma del poder? Con violencia y muerte, obviamente, con la sumisión de la población, con el asesinato, heridas y mutilaciones, con la división de los cuerpos, en resumidas cuentas. Este cuerpo, sin el cual no podemos vivir y que nos permite actuar en la sociedad, está herido, mutilado, lo que lleva consigo consecuencias inaguantables en nuestra relación con los demás, con el mundo y con la vida.

Frente al ideal del cuerpo difundido por la sociedad, se erigen cuerpos mutilados, rotos, almas heridas que desean darse a conocer y expresar sus vivencias, a pesar de la constante negación de la sociedad para otorgarles tan anhelada visibilidad. Las artes, vistas como motor social, se encargan de darles dicha visibilidad, cumpliendo una función catártica sobre la población, intentando dar las respuestas que la sociedad no puede o no quiere ofrecer. El teatro, por ser texto y representación, cumple este propósito. Es un espectáculo total, herramienta de unificación, que trata de aportar elementos para lograrla y, por lo menos, aliviar nuestra sociedad lastimada. El cuerpo se convierte en el vehículo del teatro para mostrar su esencia, su corporalidad en todas las vertientes hasta alcanzar representaciones extremas. El siglo XX alcanza unos límites bastante sombríos como consecuencia de los estragos históricos, por lo que algunos autores parten de una visión siniestra de lo orgánico, influenciados por "George Bataille, Artaud, Hans Bellmer y sus inquietantes muñecas, junto a manifestaciones más recientes como los sacrificios animales de Wols, o las automutilaciones de Günter Brus" (Vásquez Rocca, 20o8: 3).

El siglo XXI sigue esta línea de pensamiento y da protagonismo a los cuerpos en todas sus facetas, incluyendo y rechazando al mismo tiempo la visión idealista, vinculada a los medios de comunicación, del "cuerpo sano y joven, el cuerpo narcisista", para reivindicar "esa parte maldita sometida a la temporalidad, al dolor, y en último extremo a la muerte" (Vásquez Rocca, 20o8: 3). A pesar de los numerosos artistas que siguen esta línea, en este trabajo hemos elegido a una dramaturga en particular, Laila Ripoll (Madrid, I964), por su relación con la corporalidad, el interés por la historia y los grandes conflictos de la humanidad, y por último por su sexo, puesto que representa a la nueva generación de dramaturgas, formadas académicamente en la democracia. Así, es una “mujer de teatro" (Pérez-Rasilla, 2OI3a: 5), que no deja de incrementar su influencia en el mundo teatral. No solo es dramaturga, actriz y directora, sino que también participa con regularidad en encuentros o escribe artículos sobre el estado de la sociedad, el proceso de escritura teatral y la función social del dramaturgo.

Su éxito es una clara muestra de los avances en la situación de la mujer. En I99I fue cofundadora, junto a otros actores ${ }^{2}$, de su propia compañía teatral, el Micomicón, en la

\footnotetext{
${ }^{2}$ Mariano Llorente, José Luis Patiño y Juanjo Artero.
} 
que desempeña el papel de dramaturga, directora y profesora ${ }^{3}$. Sus principales armas son el humor y la ironía, lo que le permite representar el horror y las atrocidades de la guerra, decir lo indecible. Forma parte de una generación de autores procedentes de la democracia y particularmente sensible a los acontecimientos actuales, como las consecuencias de la Guerra Civil, el exilio y los problemas existenciales engendrados por el franquismo (Katona, 20I5). Su preocupación traspasa las fronteras españolas y se interesa por todo tipo de conflicto, sin importar dónde tuvo o tiene lugarł. Según Ripoll, la sociedad tiene que dar la palabra a las víctimas, condenadas al olvido por la comunidad, para entender los motivos de la barbarie, poder sanar las heridas que siguen abiertas para emprender el camino hacia un futuro mejor.

La mayor parte de su producción es un recuerdo constante de las consecuencias que han tenido sobre la población las atrocidades cometidas por los seres humanos. Nos enfrenta a nuestros miedos, obligándonos a mirar cara a cara nuestro pasado, pero siempre valiéndose del humor y la ironía, ya que "hablar de todo este espanto sin usar el humor no hay quien lo aguante, es una cosa difícilmente soportable" (Ripoll, 20II: 30). Siguiendo esta línea, escribe Pronovias (Ripoll, 2006a: I45-16I), El árbol de la esperanza (Ripoll, 2003b: 39-77), Once de marzo (Ripoll, 2006: I64-I67), La ciudad sitiada y El triángulo azul (Llorente, Ripoll, 20I4), textos en los cuales estamos frente a cuerpos de mujeres mutilados, violados, abusados por los hombres, la guerra, la sociedad, pero cuerpos de mujeres a los que la valentía y el heroísmo permiten sobrevivir y avanzar.

\section{Cuerpo fragmentado}

Las obras Once de marzo y Pronovias forman parte de una obra colectiva coordinada por Adolfo Simón y titulada Once voces contra la barbarie del 11-M (Simón, 2006), obra en la que colaboraron once dramaturgos para rendir homenaje a las víctimas de los atentados perpetrados por grupos terroristas el II de marzo de 2004 en Madrid. Con motivo del primer aniversario, las piezas fueron estrenadas en 2005 en distintos teatros de Madrid. Los objetivos de este proyecto son múltiples. Dada la proximidad cronológica de

\footnotetext{
3 En un primer momento, la compañía Micomicón centró su atención en la representación de obras del teatro clásico español, más específicamente obras del Siglo de Oro, para dedicarse, a partir de 1996 , a la representación de textos propios. Así, con La ciudad sitiada (Ripoll, 2003a), obtuvo un gran éxito y numerosos premios. Fue estrenada el I2 de febrero de I.999 en la sala "Cuarta Pared" de Madrid. Laila Ripoll obtuvo el premio "Caja España" dedicado a los textos dramáticos en I996, el premio “José Luis Alonso" de la Asociación de Directores de Escena de España en I999, el primer premio por la mejor puesta en escena del Certamen de Directoras de Escena de Torrejón de Ardoz en r999 y el premio "Arcipreste de Hita” por la mejor interpretación femenina en I999.

${ }^{4}$ En varios artículos y entrevistas, Laila Ripoll habla de la influencia de su familia en su producción teatral, así como de lo que la llevó a interesarse por el pasado reciente de su país y, de forma más general, por las atrocidades cometidas por las guerras sobre la población. Como ejemplo, podemos citar dos artículos: “Santa Perpetua” y la Trilogía Fantástica", Primer Acto, 337, 20II, 25-34 y “El teatro ante el dolor”, ADE Teatro, IOI, 2004, I93. José Henríquez trata también de esta temática en una entrevista con la artista: "Entrevista con Laila Ripoll. "Soy nieta de exiliados y eso marca"”, Primer Acto, 3IO, 2005, II8-I27. La temática del exilio le interesa también, como podemos ver en su artículo: "Estos días azules y este sol de la infancia", El teatro de papel, , o, 2009, I55-I57.
} 
los acontecimientos, numerosos espectadores vivieron de primera mano los atentados, lo que permite una conexión directa entre las obras y sus vivencias personales. Las once piezas constituyen un espacio para la reflexión y la construcción de la memoria, en el que el espectador se enfrenta a un examen de conciencia para experimentar una catarsis colectiva.

Once de marzo es una pieza breve en la que una voz de mujer, puede que una madre, cuenta la rutina de una adolescente en la mañana de los atentados. Este monólogo sumerge al público de inmediato en la narración, por la tensión dramática que producen el relato y el escenario vacío. Solo se escucha su voz. El vacío escénico representa el vacío que hay en la vida de quienes perdieron un ser querido durante la tragedia, al mismo tiempo que hace referencia a "un vacío más simbólico y más amplio, que tiene que ver con los valores sociales y morales que se han ido perdiendo en aras de un consumismo exacerbado" (Fialdini Zambrano, Sibbald, 2OII: 268). La mujer narra con todo detalle la vida cotidiana de esta joven que no tiene nombre propio, al igual que las demás personas presentes en la evocación del recuerdo, identificadas con un "nosotros", lo que permite la identificación del espectador, que se reconoce en la vida de esta familia. La identificación del público, junto con la cotidianeidad de la historia, contrasta con la brutalidad de los acontecimientos, lo que provoca un efecto de choque (Fialdini Zambrano, Sibbald, 2OII: 263-275) tanto en el público, como en el lector.

En la segunda parte nos situamos después de la tragedia, viviendo las consecuencias de los atentados a través de la televisión. Los medios de comunicación tienen un papel importante, ya que hoy en día todo es transmitido en tiempo real por la televisión, recreando la barbarie y reconstruyendo la memoria, lo que le confiere un estatus primordial, por el hecho de que "los actos de barbarie no tienen mucha razón de ser si no pueden ser transmitidos a millones de telespectadores" (Fialdini Zambrano, Sibbald, 20II: 269). El espectador vive en primera persona el dolor, la desesperación y la angustia de la búsqueda del "jersey rosa de los Reyes" (Ripoll, 2oo6b: ı66). Esta búsqueda incesante es la consecuencia del efecto de choque producido por la violencia de los hechos y su contraste con la realidad. El público está impactado, la realidad se fragmenta, al igual que para la narradora, que cuenta su vivencia con fragmentos sueltos de narración. La narradora y el público están al mismo tiempo viendo la televisión, llamando por el móvil, con los bomberos, las ambulancias, en los pasillos de los hospitales o con los taxistas y los camareros. Buscamos desesperadamente indicios del paradero de la adolescente en el escenario o entre líneas, intentando así reunificar la realidad.

A partir de este momento, ella ya no se caracteriza como un ser independiente; pero, como fragmentos de su ser, encontramos entre las imágenes "la foto de Johnny Deep entre hierros retorcidos", "el jerseycito, la ortodoncia, el anillito de plata" y "lo encontramos dentro de una enorme bolsa de plástico" (Ripoll, 2oo6b: I66-I67). Las enumeraciones presentes a lo largo del relato se asemejan no solo a la angustia de la búsqueda, sino también a los cuerpos rotos, mutilados como consecuencia del atentado. La realidad está fragmentada y los cuerpos también. Buscando la reunificación de la realidad, se 
busca a la vez la reunificación de los cuerpos que quedaron fragmentados. La narradora no se refiere a la búsqueda de la adolescente, sino solo a la búsqueda del jersey rosa, como fragmento de su ser. Asimismo, el cuerpo de la joven se convierte en mero objeto, entregado a la familia en "una enorme bolsa de basura" (Ripoll, 2oo6b: I67). El cuerpo se reunifica dentro de esa bolsa, pero no basta para reunificar la realidad. Los cuerpos destrozados se convierten así en la imagen y el símbolo de las vidas destrozadas a raíz de las atrocidades cometidas.

La “división palpable entre el mundo de afuera, violento, sin sentido, incomprensible, amenazante, y la intimidad solidaria del nosotros, en la que ya se encuentran atrapados el público y el lector" (Fialdini Zambrano, Sibbald, 20II: 269) impacta de forma brutal, pero es necesaria para iniciar el proceso de duelo y sobrevivir a la tragedia. Los lectores de la obra, así como el público, se reconocen en la vivencia de esta mujer, Ripoll universaliza su desgracia a todas las mujeres y en general a todas las personas que perdieron a un ser querido, no solo en esta tragedia sino en cualquiera. Su dolor es universal.

La segunda pieza de Laila Ripoll, Pronovias, recogida en la obra colectiva citada anteriormente, pone en escena a mujeres víctimas de los atentados del II de marzo. Se trata de un homenaje a los supervivientes de los actos terroristas, de una obra con un regusto amargo, que usa el esperpento y el humor negro. Dos mujeres están en una tienda para comprar un vestido de novia: Bea, que se va a casar con Félix, y su dama de honor, Clari. Enseguida vemos que ambas sufren las consecuencias del ataque. Bea está rapada con una cicatriz en la cabeza y se desplaza con muletas. En cuanto a Clari, le falta una pierna y está bastante sorda (Ripoll, 2006a: I45-I6I). Aquí también el enfrentamiento entre dos situaciones, dos personas con secuelas físicas intentando recrear una situación común, provoca un efecto de choque entre los espectadores y entre los lectores. Estos cuerpos rotos son un recuerdo constante tanto para el público como para ambas mujeres de la tragedia vivida (Fialdini Zambrano, Sibbald, 2OII: 27I). Cualquier acto cotidiano se convierte en un desafío, como "subir y bajar escaleras", "dormir sin dar un brinco a cada minuto", "convivir con nuestro cuerpo como si estuviera entero" o "viajar en tren" (Ripoll, 2006a: I57). La referencia a los cuerpos mutilados remite a La ciudad sitiada, en la que una muchacha cuenta el horror de un bombardeo y las consecuencias sobre su cuerpo, al que le faltan las piernas. No obstante, al igual que en Pronovias, muestra una valentía sobrecogedora y una resignación tremenda frente a los acontecimientos: "no me quejo porque soy afortunada. Tengo un carrito con el que puedo moverme de ruina en ruina” (Ripoll, 200za: II). Pese al horror de su mutilación -“en vez de muslos tenía dos muñones retorcidos. Entre los trozos de carne vi mis huesos pero no lloré” (Ripoll, 2003a: II)- sobrevive sintiéndose agradecida de estar aún viva.

Los cuerpos de estas mujeres ya no corresponden a los estereotipos vinculados a la sociedad, la misma sociedad no está hecha para estas mujeres, que se esfuerzan por tener una vida normal, usando el humor y burlándose de sí mismas para enfrentarse a su situación. Son mujeres 
conscientes de su condición tragicómica cuando encarnan el papel de novia y de dama de honor en una boda que supone para ellas un desafío no solo a las convenciones de pulcritud y estilizada impecabilidad que parecen exigirse en una ceremonia semejante, sino a las propias leyes de gravedad, puesto que [...] no pueden sostenerse sin ayuda. Sin embargo, y pese a que saben que, miradas desde fuera su porte parecerá ridículo, no están dispuestas a dejarse vencer por un patrón social ni por las secuelas del atentado (Pérez Rasilla, 20I3b: 82).

Como ellas mismas reconocen, han aprendido a vivir con sus cuerpos, los aceptan y los quieren, consiguiendo olvidarse de las partes mutiladas. El cuerpo sano y perfecto que nos proporcionará felicidad, según las leyes sociales, no es sino un envoltorio herido que no refleja el alma y el espíritu luchador de esas mujeres y de todas las víctimas. Muestran fuerza y valentía frente a una sociedad que no está preparada para acogerlas, ya que no encajan en el patrón social. No esconden sus heridas, que las hacen más fuertes, y se ríen de su condición, como en la escena en la que Clari le dice a Bea, la novia:

¿Te imaginas que ese día el cacho tubo [refiriéndose a la prótesis] le dé por hacer lo que le da la gana y se me vaya la pierna para el otro lado? ¡Qué papelón!

Sí, y yo cayéndome encima de ti, enrollada en la cola, como un kebab (Ripoll, 20o6a: I53).

Ripoll da un toque humorístico a toda la obra que se mezcla con la tragedia, con el fin de provocar la risa en el espectador, pero, como en el caso de la dependienta, con "una risilla falsa que es más una mueca que otra cosa” (Ripoll, 2006a: I53). Tanto el espectador como el lector no consiguen reírse del todo, puesto que son incapaces de superar la barrera entre ellos y estas mujeres, mientras que ellas utilizan la risa como catarsis, para asumir su condición. Estos cuerpos poseen un carácter "monstruoso", entendiéndolo como fuera de los cánones de belleza, y que "se contrapone directamente con la mirada que efectúa el otro sobre ellos” (Rovecchio Antón, 20I5a: 370).

El malestar no viene de la visión que estas mujeres tienen de sí mismas, sino de la imagen reflejada por la sociedad. Nuestra sociedad destaca por su falta de compromiso y de solidaridad frente a las víctimas de conflictos. La población, después de lanzar su mirada compasiva, se olvida de ellas, prefiriendo apartar los ojos para no ver las consecuencias de las atrocidades cometidas, sin aportarles soluciones económicas o laborales. De esta forma, Laila Ripoll lanza un "ataque mordaz a una sociedad hipócrita y contradictoria que mira con lástima a las víctimas o aparta la mirada” (López Sánchez, 2OII: II3).

El cuerpo no es solo un "cuerpo físico" sino también un "cuerpo social”, tal y como afirma la antropóloga Mary Douglas. Así, “el cuerpo social restringe el modo en que se percibe el cuerpo físico” (Douglas, r988: 93), lo que 
significa que el cuerpo es un medio de expresión altamente restringido, puesto que está muy mediatizado por la cultura y expresa la presión social que tiene que soportar. La situación social se impone en el cuerpo y lo ciñe a actuar de formas concretas; así, el cuerpo se convierte en un símbolo de la situación (Martínez Barreiro, 2004: I3o).

Además, centrándonos en la cuestión de género, se puede afirmar que la mujer desarrolla una mayor conciencia corporal que los hombres, ya que sabe que su cuerpo es un cuerpo que se mira, que el hombre mira más específicamente. Nuestra sociedad se encarga de recordarnos que tenemos que salvar y cuidar nuestro cuerpo, puesto que solo tenemos uno. Lo exhibimos a la vez como una forma de inversión y como signo social (Martínez Barreiro, 2004: I39). La novia y su dama de honor son también conscientes del proceso de socialización de su cuerpo y de lo que significa la imagen que dan de ellas mismas a través de su cuerpo. Sus cuerpos no encajan en esta sociedad de consumo, que considera el cuerpo como el mayor representante del alma. Hoy, más que nunca, "nuestra felicidad y realización personal, cada vez más, están sujetas al grado en que nuestros cuerpos se ajustan a las normas contemporáneas de salud y belleza” (Martínez Barreiro, 2004: I4O). ¿Cómo pueden vivir ambas mujeres viendo su cuerpo mutilado, viendo cómo no pueden encajar en esta sociedad? Usando el humor y la ironía. Son conscientes de su cuerpo y de sus límites, límites que llevan más allá día tras día.

Cuanto más alejados estamos del "cuerpo ideal”, más sujetos estamos a todo tipo de discriminaciones. La dependienta, al ver las dificultades a las que se enfrentan Bea y Clari, acaba aconsejándoles otro modelo:

Dep.- ¿No les interesaría ver otro modelo? [...]

Dep.- Tenemos unos modelos monísimos, con escote "palabra de honor" y con una cola mucho más ligera. ¿De verdad no quieren ver otro modelo?

Clari.- (Peleando cada vez más con la cola) No, no, nos gusta este... (Ripoll, 20o6a: I54-I55)

La dependienta no consigue su propósito. Dada la fuerza que se desprende de estas dos mujeres, están decididas a comprar el vestido que ellas quieren, independientemente de lo dificultoso que va a resultar lucirlo. Desean llevar una vida normal y por lo tanto también quieren una boda "normal". Son una muestra de superación personal, su fuerza es regeneradora y muestran que su voluntad no está determinada ni limitada por su cuerpo. Reivindican y asumen sus diferencias. Bea y Clari desafían las normas sociales que dictan que una figura agraciada, como la de la "finísima dependienta de la tienda" (Ripoll, 2006a: I47), suele experimentar ligereza y seguridad, y que en cambio un cuerpo menos agraciado sentirá incomodidad, torpeza y timidez. Aquí, todo lo contrario, la dependienta muestra inseguridad e incomodidad, mientras que ellas, a pesar de la torpeza inherente a su condición, sienten seguridad y se toman la situación con humor. 
De esta forma, Laila Ripoll homenajea a "los supervivientes de la barbarie y su lucha por seguir adelante con sus vidas, pero sin olvidar las secuelas físicas y psicológicas producidas por los atentados y los problemas económicos y laborales que acarrean su lesión” (García Manso, 20I3: 348) y que tienen que ser asumidos por medidas políticas. Asimismo, trata de exorcizar los tabúes del terrorismo, evitando el olvido y generando patrones identitarios más proclives a la tolerancia y al respeto del otro.

\section{Cuerpo herido}

Siguiendo la misma línea, pero enfocándola de forma distinta, nuestra dramaturga presenta el texto El árbol de la esperanza, publicado en 2003 y estrenado en 2007 por la Coproducción Amaya Curieses Iriarte y Micomicón. Aquí también nos enfrentamos a una mujer, víctima de múltiples lesiones a raíz de un accidente, por lo cual tiene que vivir encamada. La obra es el monólogo de esta mujer en los momentos previos a su muerte. Es un espectáculo íntimo, coincidiendo con la temática de la muerte, que constituye un acto solitario. Aunque no aparezca su nombre en la obra, adivinamos que se trata de una figura pública, Frida Kahlo, una mujer que "revolucion[ó] el lenguaje a través de su cuerpo y de su arte" (Rovecchio Antón, 20I3: 65). Convirtió su dolor en arte y belleza y, a pesar de su condición femenina, ha llegado a ser un modelo de lucha, de superación y de reivindicación, consiguiendo hacerse un nombre en la sociedad. El hecho de que no haya referencias concretas la convierte en un personaje abierto y universal, con el cual nos podemos identificar, pues representa, como en Pronovias, el coraje, la voluntad de sobrevivir y de vivir pese a todo.

La figura de la protagonista se nos presenta como una mujer deformada, con cuerpo roto debido a su enfermedad y a las numerosas operaciones que ha tenido que soportar:

Tiene cuarenta y tantos años pero aparenta el doble. Lleva dentadura postiza que, a veces, le dificulta el habla. Ha debido de ser muy hermosa, tremendamente hermosa, pero ahora solo es un poco de piel sobre unos huesos horriblemente deformados [...] Un corsé de escayola [...] le cubre el pecho y le dificulta el movimiento (Ripoll, 2003b: 4I).

Al igual que ocurre con la novia y su dama de honor, esta otra mujer utiliza la ironía y el sarcasmo para hablar de su condición, recurre a la animalización, lo excesivo y lo hiperbólico, valiéndose de todos los recursos de lo grotesco, lo que provoca un tremendo desfase entre su situación y el humor con el que es descrita (Reck, 20I2: 66). El cuerpo está en el centro de la narración, el relato se construye en torno a él y a las sensaciones que experimenta, sensaciones de dolor y de tristeza. La búsqueda del yo está latiendo en toda la obra; Frida Kahlo no se reconoce ni se siente identificada con aquello en lo que se ha convertido de mayor: "Hay veces que no sé con quién estoy hablando, pareces otra persona y no te conozco" (Ripoll, 2003b: 42). Así, a través de la creación del desdo- 
blamiento, buscando "un yo más íntimo basado en el reflejo de la evolución psicológica del individuo" (Rovecchio, 20I3: 67), la niña Frida Kahlo busca el reconocimiento de sí misma y permite a su homóloga adulta hablar libremente de sus sentimientos.

La belleza de la joven Frida -“creo que hubo un tiempo en que yo era muy guapa. La más guapa” (Ripoll, 20I3b: 49) - contrasta con su actual fealdad -“te falta una pierna, llevas un corsé horroroso y estás fea. Fea, fea [...] Terriblemente fea” (Ripoll, 2oo3b: 42) - asociando la belleza con el poder. De joven, conseguía a los hombres que deseaba, bailaba, cantaba, enseñaba los pechos, se pintaba la boca y no necesitaba nada de nadie. Encajaba en la sociedad, en la que, como ya comentamos, la belleza es sinónimo de poder y de seguridad. Ahora, por el contrario, es "una terrible belleza totalmente transformada" (Ripoll, 2003b: 57); su cuerpo está destrozado, mutilado, y necesita ayuda hasta para "limpiarse el culo". Solo le queda el humor y el sarcasmo para sobrevivir. La imagen de su cuerpo mutilado se vincula reiteradamente a una violación, pues el tranvía que la arrolla le destroza la pelvis, "entró por el mismo sitio" (Ripoll, 2003b: 7I) que una violación, por lo que ha sido "jodida, penetrada, violentada, forzada, violada, mutilada, castrada..." (Ripoll, 2003b: 72).

Laila Ripoll toca en esta pieza muchos de los temas vinculados a la condición femenina. Trata la maternidad desde dos enfoques: la relación conflictiva con la madre de la protagonista, por un lado, y por otro el hijo de Frida, que no sobrevivió debido a que ella tenía la pelvis destrozada. El cuerpo del niño muerto se fragmenta, más específicamente "partieron en trozos a [su] niño para poderlo sacar" (Ripoll, 2003b: 68). Es una visión violenta, que remite a su propio cuerpo troceado: tiene la pelvis como "un potro de tortura" (Ripoll, 2003b: 68), le falta una pierna, lleva una dentadura postiza y un corsé. Su cuerpo, al igual que el de su hijo, no le pertenece, está sometido al dolor constante e inaguantable que la llevará hasta la muerte.

El color rojo vinculado a la sangre durante el parto, a la sangre de la menstruación, la de su accidente y la de su "primer muerto" (Ripoll, 2003b: 5I), está omnipresente y siempre ligado al concepto de muerte. La protagonista sabe que la muerte la acecha, sus recuerdos no se pueden desvincular de dicha idea. El esqueleto presente, el cráneo destrozado por una bala, "las cabezas rotas y las piernas partidas" (Ripoll, 2003b: 67) son muestras violentas del final de su vida. Otra vez nos enfrentamos a cuerpos mutilados, cuya fragmentación remite a lo fragmentado de su discurso. Debido al sufrimiento y a la mezcla de medicinas y alcohol, le cuesta mantener el hilo de su discurso y divaga, habla con la Frida Kahlo niña, con el esqueleto, con su madre. A la vez recuerda su pasado, desde su niñez, la relación traumática con su madre, la lucha campesina, su primera menstruación y su falta de ella, su accidente, la felicidad de su juventud, su boda y la ausencia de su marido, la pérdida de su hijo, la visión de su futuro, hasta su propia muerte, destapando "la necesidad de asimilar los episodios pasados para construir su propio sujeto y, así, descansar en paz, pero también saber cuál es su lugar frente al mundo" (Rovecchio Antón, 2OI3: 73) de la misma forma que trata de reconstruir su cuerpo fragmentado. 
A través de la reconstrucción de su vida, trata de reconstruir su propio cuerpo. Este cuerpo, que al mismo tiempo ha sido un impedimento para lograr su felicidad, le ha permitido alcanzar la belleza, la plenitud y el reconocimiento mediante la expresión artística. Su vida y su obra están llenos de dicotomías: vida y muerte, dolor y lucha u operación y esperanza, contrastes representados por la Frida niña y la adulta, y que la han impulsado a seguir luchando. De este modo, traspasa los límites de su cuerpo reconstruyendo su memoria. Su cuerpo mutilado, fuera de las normas establecidas, y sus vivencias peculiares la han llevado a sobrepasar los límites y alcanzar el virtuosismo. Humanizando su figura, Ripoll la erige como muestra de valentía y coraje para todas las mujeres.

\section{Cuerpo poseído}

Otras muestras de valentía y coraje se encuentran en las obras La ciudad sitiada y Eltriángulo azul, textos en los que Ripoll recupera las vivencias y las voces de mujeres de las que han abusado los hombres para denunciar la violencia que sufren constantemente. En su primera obra, La ciudad sitiada, escrita en I996 y estrenada en r999 en la sala "Cuarta Pared" en Madrid, la dramaturga, de vuelta de su viaje a América Central, denuncia las consecuencias de la guerra de El Salvador sobre la población. No obstante, los personajes son anónimos y el lugar y el tiempo simbólicos con el fin de dar universalidad a su trabajo. Es un grito desgarrador contra los abusos cometidos a las poblaciones civiles en todos los conflictos, surgidos por motivos ajenos a los habitantes. El triángulo azul, obra estrenada en 2OI4, relata también las atrocidades de la guerra, pero esta vez nos situamos frente a personajes con nombre propio, y el espacio y el tiempo están claramente definidos, sin perder su afán de universalidad. En este caso, nos enfrentamos a una realidad cercana geográficamente: los españoles republicanos, perseguidos por Franco, son enviados al campo de concentración de Mauthausen, condenados a muerte por su propio país. Como en su primera obra, la autora se basa en hechos reales y documentados: estos españoles, gracias a su valentía, sacaron del campo de concentración fotografías para demostrar el horror y las atrocidades que se cometieron en él.

Dado el grado de barbarie representado en ambas obras, Ripoll recurre al humor negro y a lo grotesco para alcanzar su propósito, de modo que "la grotesquización consigue [...] compensar de alguna forma la crueldad escénica produciendo un efecto de humor, pero nunca para soslayar el efecto de horror" (Trecca, 20I6: 254). Los personajes viven en un mundo dominado por la violencia y han aprendido a convivir con ella, hasta el punto de que esta "cosa monstruosa y terrible se convierte en cotidiano" (Henríquez, 2005: 124). Por esta razón usan el humor para referirse a las atrocidades de las que han sido víctimas. El humor tiene un papel liberador, permite sobrevivir a la barbarie, es una estrategia de supervivencia, así como una fuerza de resistencia. Rememorando su experiencia en América Central, Ripoll comenta que uno de los habitantes relataba los horrores de la guerra "mientras se encend[ía] un pitillo y sonr[eía] con el fatalismo de las 
gentes centroamericanas. Nada parece grave" (Ripoll, 20I5). Estamos frente a personas torturadas, mutiladas, humilladas, violadas, frente a bebés que podrían servir de comida. El humor es, pues, la única vía para aguantar dichas atrocidades. El ser humano es desposeído de su humanidad convirtiéndose en un mero objeto, objeto utilizado para la toma de poder. Pese a no ver en escena estos actos, el juego de los actores y el papel evocador de las palabras bastan para transmitir el miedo, el dolor y la irracionalidad de lo ocurrido.

Dentro de todo este horror, aparece recurrentemente un tipo de violencia: la violación de la mujer como forma de dominación masculina. La mujer vive bajo el yugo del hombre desde tiempos inmemoriales, siendo lo masculino la norma y lo femenino la excepción de esta norma. La división entre ambos sexos es bien conocida: lo varonil se identifica con lo público, lo potente, mientras que el papel de la mujer se sitúa en lo privado, lo íntimo, siendo el confinamiento de la mujer tanto real (trabajo doméstico, cuidado de los hijos) como simbólico (estar callada, ser tímida, no sobrepasar su papel en la sociedad y dejar el protagonismo al hombre) (Bourdieu, I998). Este dominio de lo masculino está legitimado, no requiere ningún tipo de justificación, se manifiesta en las costumbres y los discursos que contribuyen a ajustar los dichos con los hechos.

La diferencia biológica entre ambos sexos, la fuerza varonil del hombre como contrapunto a la delicadeza de la mujer, es la razón que fundamenta dicho dominio. El sexo del hombre se opone al de la mujer, siendo la vagina un "falo invertido" (Pouchelle, I983), una variante del pene del hombre, o sea, una variante de la norma. Desde esta posición teórica, es lógico que hasta el acto sexual sea concebido como una forma de dominio del hombre sobre la mujer: el hombre la penetra y la posee, convirtiéndola en objeto de su propio deseo para satisfacerlo. Así, la dominación erotizada define los imperativos de la masculinidad, en tanto que lo que define la feminidad es la sumisión erotizada (Bereni, Chauvin, Janait, Revillard, 2OI2: 77). La violación es, pues, la muestra suprema de la dominación del hombre sobre la mujer, puesto que exhibe su poder y su supuesta superioridad. El sexo siempre se ha considerado como instrumento de dominio, por cuanto el acto sexual refleja esta relación. Además, el deseo sexual se ve incrementado a medida que crece lo prohibido, potenciando el deseo. Como los instintos animales son reprimidos en nuestras sociedades, durante los conflictos esos instintos vuelven a la superficie y la violación se erige como muestra del poder de los vencedores sobre los vencidos. Los hombres satisfacen su instinto animal y el deseo de posesión ligado al deseo de dominación se expresa, pues, mediante la violación. Violencia y erotismo van de la mano y, como explica Bataille en su obra L'érotisme, "l'essence de l'érotisme est la souillure" (Bataille, 2OII: I6o). La mujer es deseada, más que por instinto sexual, para ser mancillada y profanada.

Laila Ripoll muestra claramente en varias de sus obras este deseo de posesión y de dominación, refiriéndose a las violaciones y abusos de las mujeres en tiempo de guerra, no solo como estrategia bélica, sino también como brutalidad y violencia engendradas por el deseo de dominio del hombre. En La ciudad sitiada, la dramaturga presenta retratos de mujeres violadas, de las que ha abusado la autoridad, mediante la historia de siete personajes que recuerdan sus vivencias traumáticas. Tanto la ciudad sitiada como 
los personajes son anónimos, lo que les confiere un carácter simbólico, pero se vislumbra la influencia de su viaje por América Central, centrándose en los recuerdos de la guerra de El Salvador. La obra se ve influenciada también por la guerra de la antigua Yugoslavia y por los recuerdos de la Guerra Civil y la posguerra española.

Estas mujeres relatan los horrores de los abusos a los que sus cuerpos fueron sometidos. Una mujer joven narra el suceso de su violación, centrándose en las sensaciones y reviviéndolas: oye a sus agresores, huele "su aliento de borracho, avinagrado y espeso. Aliento de perro", "sus alientos ácidos" (Ripoll, 2003a: 20). Su relato es desgarrador, puesto que recalca el miedo que siente, junto con la atrocidad de la violación. Esos hombres le hicieron "probar hasta cinco babas distintas, hasta cinco alientos distintos, cinco braguetas distintas que olían todas igual. Cinco mugres distintas encima de su cuerpo" (Ripoll, 20o3a: 2I). Su cuerpo fue profanado cinco veces y golpeado "contra el lavabo, contra el quicio de la puerta y más tarde a puñetazos" (Ripoll, 2003a: 2I). Los hombres satisfacen su deseo de dominación no solo profanando su cuerpo, sino también humillándola a través de insultos y golpes. En otra escena, una mujer mayor avisa a su nieta sobre los hombres. Se trata del mismo tipo de hombres, violentos, que desprenden un hedor insoportable y que "cuando algo les gusta lo toman y punto" (Ripoll, 2oo3a: 26). Los hombres se asimilan a depredadores que anulan a la mujer, tomándola como objeto para satisfacer su deseo y humillándola de todas las formas posibles.

La prostitución es también otro rasgo de las guerras. Muchas mujeres venden su cuerpo a cambio de alimento o incluso para salvar sus vidas. De esta forma, "la aceptación de la violencia sobre sus cuerpos no debe entenderse como una claudicación, sino más bien como una muestra de valentía para que sus existencias sigan adelante" (Rovecchio Antón, 20I5b: I3). De acuerdo con el análisis de Rovecchio Antón, su corporeidad "representa el punto de partida de la rebelión, ya que encarna la defensa de la libertad y, más concretamente, de su honra” (Rovecchio Antón, 2OI5b: I3), sacrificándose por el porvenir de sus hijos. Otro personaje de la pieza que comentamos, la madre, es un ejemplo del sacrificio de su cuerpo, ya que se prostituye para dar de comer a su hijo. En su relato, alude frecuentemente al hambre y sus consecuencias sobre su cuerpo, puesto que la falta de alimento le reseca el cuerpo y le impide alimentar a su hijo. Mientras ella pide comida al hombre, él se limita a ordenarle que se suba la falda, se desabroche y se quite la blusa: “S Súbete la falda! [...] ¡Súbete más la falda! [...] ¡Desabróchate la blusa! [...] ¡Quítate la blusa!" (Ripoll, 2003a: I5-I6). El hombre no la escucha. Esta mujer no es un ser humano, es un objeto, un cuerpo para satisfacer al hombre, que ejerce su autoridad sobre ella humillándola.

La dignidad pasa a un segundo plano, lo importante es sobrevivir como sea para dar un futuro mejor a los hijos. Estas madres son una muestra de amor hacia sus hijos. El hambre y la fuerza de vivir pueden con todo, y esta situación extrema se convierte en cotidiana. Como dice la madre: "una acaba acostumbrándose a todo" (Ripoll, 2003a: 3o). En efecto, 
han aprendido a vivir bajo este estado de amenaza constante, al convertirlo en parte de su rutina, con el fin de sacar adelante sus vidas y las de los suyos. En este sentido, su honor se proyecta hacia la posibilidad que abren a sus hijos de seguir con vida a pesar del maltrato. De hecho, son conscientes de que para sobrevivir no disponen de otro camino posible: solo pueden sucumbir ante la voluntad de la autoridad opresora sin poder objetar porque esta dispone de la decisión de vida y muerte de cada uno (Rovecchio Antón, 2OI5b: I5).

De igual modo, en El triángulo azul, los abusos de la autoridad son constantes. Una mujer gitana, Oana, ofrece su cuerpo a las autoridades, siendo la prostitución su única salida para poder sobrevivir. Ella también se acostumbra a sufrir esos abusos, ya que solo dispone del arma de su cuerpo para seguir con vida a la espera de un futuro mejor:

A sobrevivir. Cada cual con sus armas. A mí, desde hace casi tres años, me violan doce seres repulsivos al día, pero estoy viva. Ya no me da asco ni vergüenza, ya no es mi cuerpo, ya no me pertenece, pero estoy viva y todavía puedo mantener una conversación contigo, todavía puedo decir yo y saber a quién me refiero, todavía tengo una vida, una conciencia y unos gramos de esperanza (Llorente, Ripoll, 20I4: 64).

El fruto de estos abusos contra el cuerpo femenino es el embarazo. Oana acaba embarazada y por lo tanto se convierte en víctima de sus opresores. La desprecian, desprecian su cuerpo y la criatura que lleva dentro. Uno de ellos la mata vaciando "el cargador de la pistola sobre el cuerpo de Oana y sale" (Llorente, Ripoll, 2OI4: II6), sin ningún tipo de consideración o respeto por su persona. Es una escena brutal, al igual que en $L a$ ciudad sitiada, en la que un niño cuenta sus recuerdos felices con su familia. Sin embargo, el efecto de choque es tremendo para el espectador y el lector cuando descubren que todo es mentira: ese niño jamás llegó a nacer, puesto que los agresores lo arrancaron del vientre de su madre:

Pero todo eso es mentira.

Son recuerdos prestados.

Yo nunca he ido de aventura,

ni he bajado a por la leche y el pan,

ni me ha reñido la vecina,

ni he ido a por moras,

[ni he recogido a un perro lobo,]

ni he devanado madejas

porque yo no he nacido.

Me arrancaron del vientre de mi madre

porque era de otra raza (Ripoll, 2003a: 34 ). 
Esta práctica es, por lo tanto, habitual en los períodos de conflicto, puesto que estos niños que no llegan a nacer son vistos como futuros posibles enemigos. Así se realiza una limpieza étnica, destruyendo la identidad personal y colectiva de las mujeres y por extensión la identidad racial o nacional. Por consiguiente, las mujeres pierden el dominio sobre su propio cuerpo, se convierten en objeto e instrumento de guerra a manos de sus agresores, con el fin de no contaminar la especie con una raza distinta a la de los vencedores. Incapaces de cambiar el transcurso de su existencia, se someten a la voluntad del dominante, pero siguen luchando en silencio, demostrando "un gran fuerza, pues impulsan la canalización de su energía en un único sujeto portador de un único objetivo:

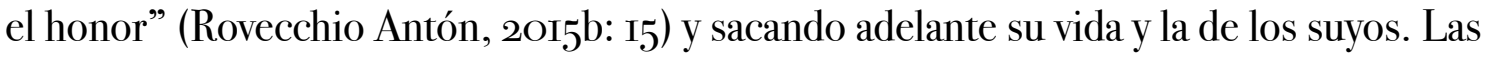
dos obras de Laila Ripoll que acabamos de comentar plantean

al público interrogantes sobre la prevalencia de la violencia en las sociedades del presente e intentan suscitar en el público una reflexión sobre los prejuicios racistas y misóginos en que se basa, con el fin de generar una conciencia colectiva más proclive a la igualdad social y a la eliminación de todas las formas de violencia (García Manso, 2OI4: I66).

\section{5. Últimas palabras}

Las mujeres desempeñan en el teatro de Laila Ripoll un papel de gran relevancia por su valor y lucha constante. No se rinden bajo ningún pretexto. No importa si sufren violaciones, mutilaciones, enfermedades. Sus cuerpos, a pesar de estar rotos, son el recuerdo de los sufrimientos vividos y muestra de su coraje. Sus vivencias no afectaron a su alma, o solo para convertirla en más fuerte. Sus almas siguen intactas, son capaces de desvincularse de su propio cuerpo y de los estereotipos engendrados por la sociedad. Se esfuerzan por encontrar un lugar en la sociedad, pese a sus diferencias.

Hemos analizado la problemática del cuerpo de la mujer en Once de marzo, donde lo cotidiano contrasta con la brutalidad de los hechos, mientras que en Pronovias la autora utiliza el humor y la tragedia para hablar de mujeres mutiladas. También es un cuerpo mutilado el de la pintora Frida Kahlo en El árbol de la esperanza, aunque convierte en arte su dolor para dar sentido a su vida. Los temas de la penetración, fecundación y posesión mediante la violencia son omnipresentes en La ciudad sitiada y El triángulo azul. Estas mujeres aceptan los abusos cometidos contra su cuerpo y su individualidad, no como debilidad, sino como una muestra de valor, y se oponen a la dominación masculina para sobrevivir.

Tanto el espectador como el lector de las obras de Laila Ripoll no tienen más remedio que enfrentarse a sus miedos y asumir su parte de responsabilidad. Tienen que mantenerse firme, como estas mujeres heroicas que son capaces de instaurar una imagen estética a través de su cuerpo en escena. Imagen que no corresponde a la norma social, pero que corresponde a lo que son, a sus vivencias e historia particular. 


\section{Referencias bibliográficas}

- Bataille, G. (20II). L'érotisme. París: Éditions de Minuit.

- Bereni, L.; Chauvin, S.; Jaunait, A. y Revillard, A. (2OI2). Introduction aux études sur le genre. Louvain-la-Neuve: De Boeck.

- Bourdieu, P. (1998). La domination masculine. París: Seuil.

- Deleuze, G. (1985). L'image-temps. París: Editions de Minuit.

- Douglas, M. (1988). Símbolos naturales: exploraciones en cosmología. Madrid: Alianza.

- Fialdini Zambrano, R. y Sibbald, K. (2OII). El efecto "de choque" en el teatro breve de Laila Ripoll. En J. Romera Castillo, F. Gutiérrez Carbajo, M. Sanfilippo (Coords.), El teatro breve en los inicios del siglo XXI (pp. 263-275). Madrid: Visor.

- García Manso, L. (20I3). Género, identidad y drama histórico escrito por mujeres en España (I975-2OIO). Oviedo: KRK ediciones.

- García Manso, M. L. (20I4). Las guerras de la ex Yugoslavia en la creación dramática española. Revista de Escritoras Ibéricas, 2, I45-I69. Obtenido el 24 de agosto de 2016 desde http:/ / revistas.uned.es/index.php/REI/article/view/I2I43

- Henríquez, J. (2005). Entrevista con Laila Ripoll. "Soy nieta de exialiados y eso marca". Primer Acto, 310, II8-I3O.

- Katona, E. (2OI5). El tema de la guerra en "La ciudad sitiada" de Laila Ripoll. Anagnórisis. Revista de Investigación Teatral, I2, I5 $5^{\mathrm{I}-\mathrm{I} 72 .}$. Obtenido el 24 de agosto de $20 \mathrm{O} 6$ desde http:// anagnorisis.es/pdfs/numı2.pdf

- Llorente, M., y Ripoll, L. (2014). El triángulo azul. Madrid: Instituto Nacional de Artes Escénicas y de Teatro.

- López Sánchez, L. (2OII). La barbarie del II-M en el teatro español. Signa: Revista de la Asociación Española de Semiótica, 20, IOI-II8. Obtenido el 24 de agosto de 2016 desde http:// www.cervantesvirtual.com/obra/la-barbarie-del-II-m-en-el-teatro-espanol-the-barbarity-ofmarch-II-in-spanish-theater/

- Martínez Barreiro, A. (2004). La construcción social del cuerpo en las sociedades. Papers: Revista de Sociología, 73, I27-I52. Obtenido el 24 de agosto 2016 desde http://papers.uab. cat/article/view/v73-martinez/pdf-es 
- Pérez-Rasilla, E. (2OIza). La trilogía de la memoria, Laila Ripoll. En L. Ripoll La trilogía de la memoria. Atra bilis, Los niños perdidos, Santa Perpetua (pp. 5-I9). Bilbao: Artezblai.

- Pérez Rasilla, E. (20I3b). El teatro de Laila Ripoll. La polifonía de la memoria. Cuadernos de Dramaturgia Contemporánea, 18,77-89.

- Pouchelle, M.-C. (1983). Corps et chirurgie à l'apogée du Moyen Âge. París: Flammarion.

- Reck, I. (2012). El teatro grotesco de Laila Ripoll. Signa: Revista de la Asociación Española de Semiótica, 2I, 55-84. Obtenido el 24 de agosto de 2016 desde http://www.cervantesvirtual. com/obra/el-teatro-grotesco-de-laila-ripoll-autora/

- Ripoll, L. (2003a). La ciudad sitiada. En L. Ripoll, La ciudad sitiada. Elárbol de la esperan$z a$ (pp. 5-37). Madrid: La Avispa.

- Ripoll, L. (2003b). El árbol de la esperanza. En L. Ripoll, La ciudad sitiada. El árbol de la esperanza. (pp. 39-77). Madrid: La Avispa.

- Ripoll, L. (2006a). Pronovias. En A. Simón, Once voces contra la barbarie del 11-M (pp. I45I6I). Madrid: Fundación Autor.

- Ripoll, L. (2006b). Once de marzo. En A. Simón, Once voces contra la barbarie del n-M (pp. ı64-I67). Madrid: Fundación Autor.

- Ripoll, L. (2OII). “Santa Perpetua” y la trilogía fantástica. Primer Acto, 377, 25-38.

- Ripoll, L. (20I5). La ciudad sitiada. Muestra de Teatro Español de Autores Contemporáneos. Obtenido el 24 de agosto de 2016 desde http://muestrateatro.com/obra/la-ciudadsitiada/

- Rovecchio Antón, L. (20I3). Monólogos a dos voces: "Mascando ortigas" de Itziar Pascual y "El árbol de la esperanza" de Laila Ripoll. Cuadernos de Investigación Filológica, 39, 63-76. Obtenido el 24 de agosto de 2016 desde https://publicaciones.unirioja.es/ojs/index.php/ cif/article/view/2555

- Rovecchio Antón, L. (20I5a). Memoria e identidad en el teatro de Laila Ripoll, Angélica Liddell Itziar Pascual (tesis doctoral). Universitat de Barcelona: Barcelona.

- Rovecchio Antón, L. (2OI5b). Una relectura de la "Numancia" de Cervantes: "La ciudad sitiada” de Laila Ripoll. En I. Rouane Soupault y P. Meunier, Tiempo e historia en el Teatro del Siglo de Oro (pp. 408-4I6). Aix en Provence: Presses Universitaires de Provence.

- Simón, A. (2006). Once voces contra la barbarie del 11-M. Madrid: Fundación Autor. 
- Trecca, S. (2016). Funciones dramáturgicas de la música en las puestas en escena de "Cancionero republicano" y "El triángulo azul”, de Mariano Llorente y Laila Ripoll. En J. Romera Castillo (Coord.), F. Gutiérrez Carbajo (Coord.) y R. García-Pascual (Coords.), Teatro y música en los inicios del siglo XXI (pp. 247-258). Madrid: Editorial Verbum.

- Vásquez Rocca, A. (2008). Las metáforas del cuerpo en la filosofía de Jean-Luc Nancy: nueva carne, cuerpo sin órganos y escatología de la enfermedad. Nómadas. Revista Crítica de Ciencias Sociales y Jurídicas, I8(2). Obtenido el 24 de agosto de 2016 desde https://revistas.ucm. es/index.php/NOMA/article/view/27537 